Williams Smith, H. (1951). J. gen. Microbiol. 5, 458-471.

\title{
Some Observations on Lysogenic Strains of Salmonella
}

\author{
By H. WILLIAMS SMITH \\ Animal Health Trust, Livestock Research Station, \\ Houghton Grange, Huntingdon
}

\begin{abstract}
SUMMARY: The proportion of lysogenic cultures in five species of salmonella examined varied from $84 \%$ in Salmonella thompson to $0 \%$ in S. pullorum.

When estimating the amount of phage present in lysogenic cultures of $\boldsymbol{S}$. thompson it was possible to obtain a plaque count approximately equal to the number of bacteria present in these cultures when the susceptible culture used for determining the counts was used relatively dilute. When used less dilute the counts were lower and equal to those obtained when the bacteria were killed by heating to $56^{\circ}$ for $30 \mathrm{~min}$. This lower figure is an estimate of the free phage in the culture.
\end{abstract}

Plaque size varied inversely as the amount of bacteria in the susceptible culture. When lysogenic cultures were used for counting a related phage, plaque size was diminished by partial interference.

Two types of relationship were noted between the growth rate of bacteria and phage in artificially induced lysogenic cultures of $S$. thompson. In one, the number of free phage particles was always directly related to the number of viable bacteria present; in the other, the phage particles increased rapidly in number during the logarithmic phase of bacterial multiplication and then decreased rapidly due presumably to their absorption by the bacteria.

The active infection of the lysogenic cultures with an unrelated phage usually resulted in an increased yield of the phage with which the culture was latently infected. In one instance the latent infection was transformed into an active one.

All the artificially induced resistant variant strains of $S$. thompson were lysogenic. It was impossible to make some cultures permanently resistant to two different phages as the resulting cultures were unstable and soon showed signs of active infection. Others were made with a difficulty not experienced during the making of singly resistant strains. Móst of these were latently infected only with the first phage to which they had been made resistant; others carried both phages.

A considerable amount of work has been devoted to the study of active bacteriophage infection. Much less time has been spent on the examination of the host-parasite relationship in lysogenic bacteria, and in this field most of the work has been carried out on naturally occurring lysogenic strains. It has been shown that some of these strains are latently infected with more than one phage and that some bacteria may be made resistant to a phage, and yet not become latently infected with it. It is therefore obvious that critical studies should best be made on strains made lysogenic by laboratory procedures. For the preparation of these cultures, strains proved, as far as possible, to be nonlysogenic and not to have become resistant to phages after infection should be used; and from these strains variants prepared that are resistant to pure phages. The main purpose of this paper is to present some observations on such lysogenic cultures of salmonella. 


\section{MATERIALS AND METHODS}

The identification of lysogenic strains. Lysogenic strains were identified by a modification of the cross-culture method (Fisk, 1942). Strains were grown in nutrient broth for $18 \mathrm{hr}$. at $37^{\circ}$; and each was used in turn as a 'basal' strain by spreading four drops $(0.08 \mathrm{ml}$.) of the culture over the whole surface of a nutrient agar plate. The plates were then dried and the remaining cultures, after heating to $56^{\circ}$ for $30 \mathrm{~min}$., were 'spotted' on to it. This process of killing the bacteria in the cultures without destroying the phage that may be present is referred to below as heat treatment. The plates were incubated for $6-8 \mathrm{hr}$. at $37^{\circ}$, and left at room temperature overnight. Phage action was revealed the next morning by zones of complete or semi-complete lysis, or by discrete plaques. Modifications of this method were used when necessary or convenient. Sometimes one known susceptible strain only was used as the basal strain. When repeated tests were necessary to prove lysogenicity, young and $18 \mathrm{hr}$. cultures, both heat treated and alive, were used for spotting. Sometimes a number of strains were incubated together in broth and, after heat treatment, the product tested for phage.

Purification and propagation of phages. Since pure phage preparations can be obtained only by propagation on non-lysogenic strains (see below), phages were propagated on strains shown by repeated testing to be non-lysogenic. (The word 'strain' is used throughout with reference to bacteria and not to phages.) A suitably diluted suspension of a heat-treated lysogenic strain was mixed with a broth culture of the propagating strain and spread on nutrient agar and incubated at $37^{\circ}$. A discrete plaque was picked as soon as plaques were distinctly visible and replated with the propagating strain. This process was repeated twice. Finally, a discrete plaque with some of the surrounding bacterial growth was picked into broth, and incubated at $37^{\circ}$ until lysis occurred. This was then heat treated, and tested for bacteriological sterility. The phages were designated by the number of the lysogenic strain from which the phage was derived followed by the number of the propagating strain.

Titration of phage preparations. Ten-fold dilutions of the phage preparations were made with quarter-strength Ringer's solution. Four drops (0.08 ml.) of an $18 \mathrm{hr}$. broth culture of a strain were spread over the surface of an agar plate, allowed to dry, and then spotted with a standard loopful of each dilution of the phage preparation. The plates were incubated at $37^{\circ}$ for $18 \mathrm{hr}$., and read.

Preparation of phage-resistant strains. One drop of an $18 \mathrm{hr}$. broth culture of a susceptible strain was spread over a small area of the surface of an agar plate. When this was dry, one drop of an undiluted phage preparation was spotted on to the surface of the culture which was then incubated at $37^{\circ}$. A zone of complete lysis was observed after 4-5 hr. Incubation was continued until secondary growth appeared within this zone. A little of this secondary growth was picked off into broth, and incubated overnight, the culture plated on agar and a single colony picked and replated, finally a single colony from this plating was picked into broth, and incubated. The final culture was tested on agar to confirm its complete resistance to the undiluted phage preparation. Its 
colonial morphology was also examined. Only cultures that yielded colonies normal in appearance were retained; any forming colonies with a nibbled appearance were regarded as actively phage-infected and were discarded. Resistant strains were designated by the number of the susceptible strain followed by the number in parenthesis of the phage to which it had been made resistant. The words 'resistant strain' are used throughout this paper to mean phage-resistant strains.

Cross-resistance tests. These were carried out by a modification of Bail's (1923) original method. Resistant strains were prepared by the action of several phages on one bacterial strain. The phages were then titrated against each of the resistant strains in the manner previously described.

Table 1. The occurrence of lysogenic strains in different species of salmonella

$\begin{array}{lccc}\text { Species } & \begin{array}{c}\text { No. of strains } \\ \text { tested }\end{array} & \begin{array}{c}\text { No. of lysogenic } \\ \text { strains }\end{array} & \begin{array}{c}\text { Percentage of } \\ \text { lysogenic strains }\end{array} \\ \text { S. thompson } & \mathbf{5 0} & \mathbf{4 2} & \mathbf{8 4} \\ \text { S. typhi-murium } & \mathbf{5 0} & \mathbf{1 3} & \mathbf{2 6} \\ \text { S. dublin } & 67 & 14 & 20 \cdot 9 \\ \text { S. } \text { enteritidis } & \mathbf{2 0} & \mathbf{4} & \mathbf{2 0} \\ \text { S. pullorum } & 62 & 0 & 0\end{array}$

Bacterial counts. These were carried out by the method of Miles \& Misra (1938).

Phage counts. A modification of the Miles \& Misra (1938) method for bacterial counts was used for this purpose. Two per cent nutrient agar plates were dried for $24 \mathrm{hr}$. at $37^{\circ}$ followed by a further $2 \mathrm{hr}$. with the lids raised. Four drops $(0.08 \mathrm{ml}$.) of an $18 \mathrm{hr}$. broth culture of a susceptible strain were spread evenly over the surface of these plates, and drying was continued for another 1-1 $\frac{1}{2} \mathrm{hr}$. with the lids raised. The area covered by the culture is referred to as the bacterial lawn. The fluid to be examined for its phage content was heat treated. The plates were incubated at $37^{\circ}$ for $18 \mathrm{hr}$. before plaque counts were made.

All the bacterial cultures used were smooth unless otherwise stated. The expressions 'lysogenic', carrying phage', and 'latently infected with phage' are used synonymously.

\section{RESULTS}

\section{The occurrence of lysogenic strains amongst different species of salmonella}

Representative species of salmonella were examined for lysogenicity. The tests were carried out within species only, e.g. the Salmonella enteritidis strains were only tested for lysogenicity to other strains of that species. Table 1 illustrates the considerable difference in the proportion of lysogenic strains within different species, varying from $84 \%$ for $S$. thompson to $0 \%$ for $S$. pullorum. The figures for $S$. enteritidis $(20 \%)$ are considerably lower than those, for example, of Burnet (1932) who found fifteen of eighteen smooth strains to be lysogenic. Because Burnet found a strain of $S$. gallinarum to be a very suitable indicator for these lysogenic strains, six strains of $S$. gallinarum were used as indicators for the twenty $S$. enteritidis strains tested. They did not reveal any more strains to be lysogenic. It is probable, however, that if a more thorough search for 
suitable indicator strains were made, more strains would be shown to be lysogenic. Since a high proportion of the $S$. thompson cultures were lysogenic, and as a preliminary examination of the phages carried by some of these cultures showed many of the phages to be different from each other, it was decided to use the $S$. thompson strains for more detailed studies.

Nine phages isolated from lysogenic cultures of $S$. thompson were titrated against the fifty strains of $S$. thompson referred to in Table 1 . Of the eight nonlysogenic strains, six were resistant in varying degrees to the phages, and two, strains 19 and 30, were fully susceptible to all the nine phages. Thus strains 19 and 30 appeared to be non-lysogenic, and to have acquired no resistance to bacteriophages and were therefore ideal for this investigation.

Most of the nine phages had been propagated on lysogenic strains. Consequently, they were contaminated with phages contributed by the strains; and were accordingly purified and propagated on strain 19.

Variants resistant to these nine phages were prepared from strain 19; all were lysogenic. By cross-resistance tests six of these phages, 1/19, 2/19, 5/19, $7 / 19,8 / 19$ and $13 / 19$, were shown to be quite different from each other. One interesting feature of some of these tests was that of partial interference, as shown by the appearance of plaques of subnormal size in some of the titrations. These plaques were often quite minute and difficult to discern.

\section{The growth rate of bacteria and phage in lysogenic strains}

It was necessary to estimate the probable phage mortality during heat treatment. Four of the phages were freed from bacteria by Seitz filtration. One portion of the filtrate was heated to $56^{\circ}$ for $30 \mathrm{~min}$. Phage counts of both portions (Table 2) indicated that the loss during heating was negligible.

Table 2. The effect of heating phage preparations to $56^{\circ}$ for $30 \mathrm{~min}$.

Phage particles, $10^{4} / \mathrm{ml}$.

$\begin{array}{ccc}\text { Phage } & \overbrace{}^{\text {Before heating }} & \text { After heating } \\ 7 / 19 & 70 & 80 \\ 8 / 19 & 48 & 38 \\ 2 / 19 & 28 & 20 \\ 5 / 19 & 28,000 & 30,000\end{array}$

Nutrient broth at $37^{\circ}$ in $20 \mathrm{ml}$. amounts was seeded with $0.1 \mathrm{ml}$. of an $18 \mathrm{hr}$. culture of a lysogenic strain and incubated at $37^{\circ}: 0 \cdot 1 \mathrm{ml}$. samples were removed at intervals and used for bacterial and phage counts, the phage counts being made of an unheated and a heat-treated portion, upon plates seeded with strain 19. Seven lysogenic variants of strain 19 carrying different phages were examined. The variants, apart from differences in the yield of phage, could be classified into two types, types 1 and 2, containing respectively three and four variants.

Type 1. The results obtained with strain $19(5 / 19)$ are representative of type 1 (Table 3 and Fig. 1). The phage population of the culture was directly related to the number of visible bacteria present, both in the logarithmic phase 
Table 3. The growth rate of bacteria and phage in culture $19(5 / 19)$

\begin{tabular}{|c|c|c|c|c|}
\hline \multirow{2}{*}{\multicolumn{2}{|c|}{ Time }} & \multirow{2}{*}{$\begin{array}{c}\text { Viable } \\
\text { bacteria, } \\
10^{\circ} / \mathrm{ml} .\end{array}$} & \multicolumn{2}{|c|}{ Viable phage particles, $10^{6} / \mathrm{ml}$} \\
\hline & & & Using live culture & $\begin{array}{l}\text { Using heat-treated } \\
\text { culture }\end{array}$ \\
\hline & hr. & $4 \cdot 2$ & $\mathbf{0 \cdot 2 1}$ & 0.2 \\
\hline & „, & $5 \cdot 2$ & 0.23 & 0.25 \\
\hline & & $5 \cdot 5$ & $0 \cdot 31$ & 0.3 \\
\hline & & $12 \cdot 0$ & 1.0 & 0.6 \\
\hline & & $28 \cdot 0$ & 1.2 & 0.85 \\
\hline & & $50 \cdot 0$ & - & 1.7 \\
\hline 3 & & $80 \cdot 0$ & $7 \cdot 3$ & 5.5 \\
\hline & ", & $230 \cdot 0$ & $19 \cdot 0$ & $12 \cdot 0$ \\
\hline 4 & ", & $340 \cdot 0$ & $29 \cdot 0$ & $22 \cdot 0$ \\
\hline & $"$ & $450 \cdot 0$ & $37 \cdot 0$ & $32 \cdot 0$ \\
\hline & ", & - & - & $46 \cdot 0$ \\
\hline 6 & ", & $550 \cdot 0$ & $50 \cdot 0$ & $52 \cdot 0$ \\
\hline & ", & $400 \cdot 0$ & $70 \cdot 0$ & $90 \cdot 0$ \\
\hline 10 & ", & $520 \cdot 0$ & 85.0 & $90 \cdot 0$ \\
\hline 12 & $"$ & $500 \cdot 0$ & $65 \cdot 0$ & $65 \cdot 0$ \\
\hline 14 & & $490 \cdot 0$ & $56 \cdot 0$ & $100 \cdot 0$ \\
\hline 16 & ", & $480 \cdot 0$ & $50 \cdot 0$ & $78 \cdot 0$ \\
\hline 18 & & $750 \cdot 0$ & $70 \cdot 0$ & $85 \cdot 0$ \\
\hline 24 & $"$ & $1400 \cdot 0$ & $110 \cdot 0$ & $100 \cdot 0$ \\
\hline $4 \mathrm{~d} g$ & lays & $500 \cdot 0$ & $100 \cdot 0$ & $250 \cdot 0$ \\
\hline 7 & , & $120 \cdot 0$ & 130.0 & $150 \cdot 0$ \\
\hline 15 & ", & $90 \cdot 0$ & $35 \cdot 0$ & $40 \cdot 0$ \\
\hline 25 & ", & $40 \cdot 0$ & $42 \cdot 0$ & $\mathbf{3 6 \cdot 0}$ \\
\hline
\end{tabular}

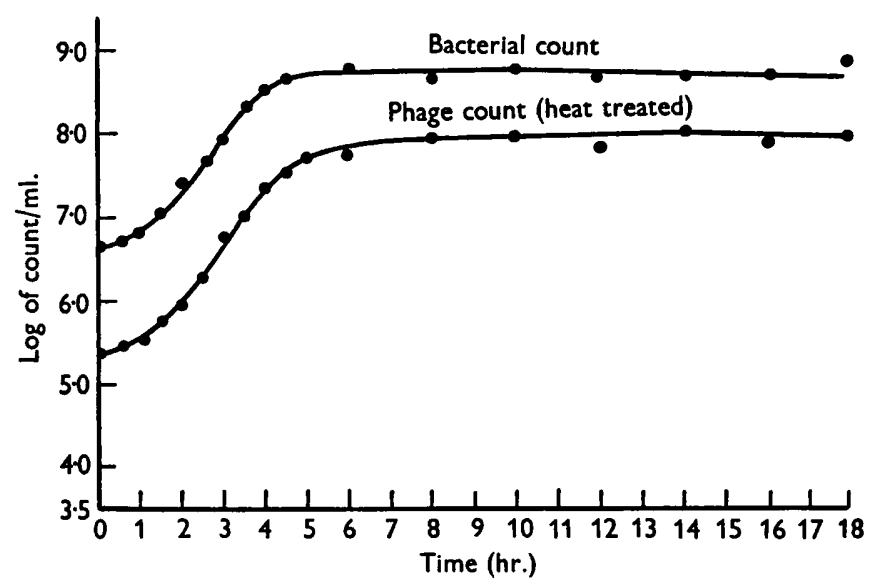

Fig. 1. The growth rate of bacteria and phage in the lysogenic culture $19(5 / 19)$.

and in the stationary bacterial phase. As the number of viable bacteria decreased, the number of phage particles also decreased but at a slower rate. This experiment was repeated with similar results. Another three variants of strain 19 resistant to phage 5/19 and two variants of the other non-lysogenic strain 30 resistant to this phage behaved in several tests like the original strain $19(5 / 19)$ although the yield of phage varied. 
Type 2. The results obtained with strain 19 (1/19) are representative of type 2 (Table 4 \& Fig. 2). In this case the initial inoculum contained a small amount of phage, but, as the culture entered the logarithmic phase, the phage increased more rapidly than the bacteria. At the end of the bacterial logarithmic phase, the number of phage particles rapidly decreased by about $90 \%$ in $1 \mathrm{hr}$. and then decreased much more slowly. This experiment was repeated twice with similar results. The occurrence of a peak in the phage count followed by a rapid decline was found to be independent of the time of incubation, but dependent on the number of multiplying bacteria present, the peak occurring near the end of the logarithmic phase when the culture contained approximately $30 \times 10^{7}$ bacteria/ml.

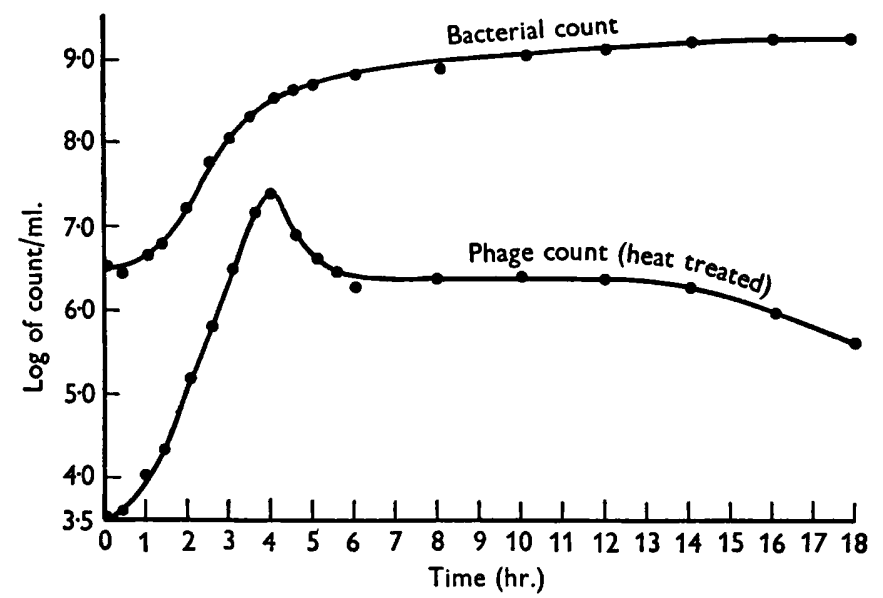

Fig. 2. The growth rate of bacteria and phage in the lysogenic culture $19(1 / 19)$.

Another two variants of strain 19 resistant to phage 1/19 and two variants of strain 30 resistant to this phage were also like the original strain 19 (1/19).

Three variants resistant to phage $1 / 19$, strains $2(1 / 19)$, were also prepared from a naturally occurring lysogenic strain, strain 2 . Bacterial and phage counts were made on cultures after 3 and $18 \mathrm{hr}$. incubation (Table 5). Phage counts were made using strain 2 as the bacterial lawn to estimate the amount of $1 / 19$ present and using strain $19(1 / 19)$ to estimate the amount of the strain 2 phage. At $18 \mathrm{hr}$., though not at $3 \mathrm{hr}$., variant $2(1 / 19) a$ and $2(1 / 19) c$ differed in phage production from $2(1 / 19) b$ which contained 100 times more phage of each kind than the other two. It is noteworthy that the amount of phage present in strains 19 (1/19) and strain 2, which are each carrying only one type of phage, was greater than the total present in cultures of the variants carrying the two phages. When these experiments were repeated the results were similar.

\section{Phage counts of lysogenic strains using live instead of heat-treated cultures}

The similarity of phage counts of living and heat-treated lysogenic strains (Tables 3 and 4) is surprising, if it is assumed that all bacteria in a lysogenic culture contain phage, or phage precursor, which might be expected to be 
released from living but not dead cultures. The counts, however, represent only free phage. Phage counts on heat-treated and live cultures and on centrifuged live $18 \mathrm{hr}$. cultures of strain 19 (5/19) were also similar being respectively 85, 70 and 73 millions per $\mathrm{ml}$. The centrifuged deposit of bacteria obtained after

Table 4. The growth rate of bacteria and phage in culture 19 (1/19)

\begin{tabular}{|c|c|c|c|c|}
\hline \multirow{2}{*}{\multicolumn{2}{|c|}{ Time }} & \multirow{2}{*}{$\begin{array}{c}\text { Viable } \\
\text { bacteria, } \\
10^{6} / \mathrm{ml} .\end{array}$} & \multicolumn{2}{|c|}{ Viable phage particles, $10^{6} / \mathrm{ml}$. } \\
\hline & & & Using live culture & $\begin{array}{l}\text { Using heat-treated } \\
\text { culture }\end{array}$ \\
\hline & hr. & $3 \cdot 0$ & 0.004 & 0.0032 \\
\hline & , & $2 \cdot 7$ & - & 0.0044 \\
\hline $1^{2}$ & , & $\mathbf{4 \cdot 4}$ & - & 0.015 \\
\hline $1 \frac{1}{2}$ & ", & 5.7 & $0 \cdot 05$ & 0.033 \\
\hline 2 & ", & $15 \cdot 0$ & $0 \cdot 17$ & $0 \cdot 18$ \\
\hline $2 \frac{1}{2}$ & ," & $55 \cdot 0$ & 0.48 & $0 \cdot 8$ \\
\hline 3 & ,, & $120 \cdot 0$ & $2 \cdot 6$ & $3 \cdot 8$ \\
\hline $3 \frac{1}{2}$ & ", & $220 \cdot 0$ & $11 \cdot 0$ & $15 \cdot 0$ \\
\hline 4 & , & $300 \cdot 0$ & $16 \cdot 0$ & $22 \cdot 0$ \\
\hline & „" & $380 \cdot 0$ & - & $7 \cdot 6$ \\
\hline 5 & " & $450 \cdot 0$ & $2 \cdot 0$ & $3 \cdot 1$ \\
\hline $5 \frac{1}{2}$ & ," & $600 \cdot 0$ & $\mathbf{1 . 9}$ & $2 \cdot 6$ \\
\hline 6 & ", & $550 \cdot 0$ & - & $\mathbf{2 \cdot 0}$ \\
\hline 8 & ,, & $800 \cdot 0$ & $3 \cdot 6$ & $\mathbf{3} \cdot \mathbf{0}$ \\
\hline 10 & ," & $1000 \cdot 0$ & - & $\mathbf{3 \cdot 0}$ \\
\hline 12 & ,, & $1100 \cdot 0$ & - & $2 \cdot 8$ \\
\hline 14 & ,, & $1900 \cdot 0$ & - & $1 \cdot 7$ \\
\hline 16 & ", & - & - & $0 \cdot 8$ \\
\hline 18 & $"$ & $1600 \cdot 0$ & 0.54 & $0 \cdot 4$ \\
\hline $5 \mathrm{~d} z$ & lays & $120 \cdot 0$ & - & 0.52 \\
\hline
\end{tabular}

Table 5. Phage counts of variants of the lysogenic strain 2, resistant to phage $1 / 19$

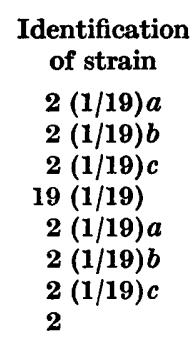

Phage particles, $10^{4} / \mathrm{ml}$. of culture

$$
\begin{gathered}
\text { Count of phage } \\
1 / 19 \\
1 / 19 \\
1 / 19 \\
1 / 19
\end{gathered}
$$

Phage carried by strain 2 Phage carried by strain 2 Phage carried by strain 2 Phage carried by strain 2

$\begin{array}{rr}3 \mathrm{hr} . & 18 \mathrm{hr} . \\ 34.0 & 0 \cdot 12 \\ 45 \cdot 0 & 30 \cdot 0 \\ 35 \cdot 0 & 0 \cdot 2 \\ 260 \cdot 0 & 40 \cdot 0 \\ 190 \cdot 0 & 2 \cdot 2 \\ 250 \cdot 0 & 200 \cdot 0 \\ 200 \cdot 0 & 2 \cdot 0 \\ 2200 \cdot 0 & 2400 \cdot 0\end{array}$

centrifuging the live culture was washed in quarter-strength Ringer's solution several times and then made up to the original volume of culture with broth. The phage count was now only 70,000 particles per ml. although there was little alteration in the bacterial count. Thus, under the condition of test, the counts were uninfluenced by the phage carried within the bacteria cells and represent free phage only.

However, when counting phage on living cultures of $19(1 / 19)$ on rather moist bacterial growth, two kinds of plaque appeared. One type was large and characteristic of phage $1 / 19$, and in numbers similar to those in heat-treated 
cultures. The other was of small size. Well-dried plates were now seeded with strain 19 , but the count dilutions were dropped on to the agar immediately the inoculum was dry. Both live and heat-treated culture, and the supernatant fluids of these cultures after centrifuging, were counted (Table 6). The count of the small plaques is probably underestimated, since some of them were very difficult to discern. It was obvious that the increase in phage count due to the

Table 6. Plaque counts of an $18 \mathrm{hr}$. broth culture of strain 19 (1/19) using a bacterial lawn unincubated before carrying out the counts

Live broth culture
Supernatant of centrifuged
broth culture
Heat-treated broth culture
Supernatant of centrifuged
heat-treated broth culture

$\begin{array}{cc}\text { No. of normal } & \text { No. of small } \\ \text { plaques, } 10^{4} / \mathrm{ml} . & \text { plaques, } 10^{4} / \mathrm{ml} . \\ 85 & 400 \\ 100 & 0 \\ 87 & \\ 75 & 0\end{array}$

plaques of subnormal size was related to the presence of live bacteria, and it seemed probable that the multiplication of these bacteria after being dropped on the lawn of susceptible culture resulted in the release of phage particles which were responsible for the increased count. The fact that these small plaques were not apparent on plates used after the bacterial lawn had been allowed to dry and incubate for 1-1 $\frac{1}{2} \mathrm{hr}$. may be accounted for by assuming that phage liberated during multiplication of the lysogenic bacteria is unable to form plaques in the much denser bacterial growth present after $1-1 \frac{1}{2} \mathrm{hr}$. incubation of the lawn.

The relation of plaque count and the time of incubation of the bacterial lawn before spotting on the count dilutions was now determined. Phage counts were made of cultures of 19 (5/19) and 19 (1/19), and supernatant fluids of these cultures after centrifuging upon plates of strain 19 incubated for different periods. These plates had been well dried before sowing the bacterial lawns and the count dilutions were quickly absorbed, so that extra plaques formed would have developed from phage particles liberated by developing colonies of the lysogenic bacteria, one plaque representing one colony (Table 7). Live broth cultures of strains $19(5 / 19)$ and (1/19) gave higher plaque counts when seeded immediately after sowing the bacterial lawn or after $\frac{1}{2} \mathrm{hr}$. incubation, than those of free phage present in the supernatant fluids of the centrifuged cultures, and higher than those obtained on agar plates that had been incubated for $1 \mathrm{hr}$. or more. The higher count can be accounted for by plaques of subnormal size. Counts on lawns incubated for 1-1 $\frac{1}{2} \mathrm{hr}$. correspond to the free phage present (cf. Tables 3 and 4). With 2-3 hr. incubation before 'spotting' the plaques size was considerably smaller, often pin-point in size, making counting difficult, and showing that the amount of bacterial lawn has a pronounced effect on plaque size. With $4 \mathrm{hr}$. incubation the amount of bacterial lawn was such that no plaques became visible.

Since the amount of bacterial lawn influenced the phage counts, an attempt 
Table 7. The effect of incubating the bacterial lawn on phage count plates before seeding with live lysogenic bacteria

3 hr. culture $19(5 / 19)$

\begin{tabular}{|c|c|c|c|c|c|c|c|c|}
\hline \multirow{3}{*}{$\begin{array}{c}\text { Time of } \\
\text { incubation } \\
\text { of bacterial } \\
\text { lawn } \\
\text { (hr.) }\end{array}$} & \multirow{2}{*}{\multicolumn{2}{|c|}{ Untreated }} & \multirow{2}{*}{\multicolumn{2}{|c|}{$\begin{array}{c}\begin{array}{c}\text { Supernatant } \\
\text { fluid after } \\
\text { centrifugation }\end{array} \\
\end{array}$}} & \multirow{2}{*}{\multicolumn{2}{|c|}{ Untreated }} & \multirow{2}{*}{\multicolumn{2}{|c|}{$\begin{array}{c}\begin{array}{c}\text { Supernatant } \\
\text { fluid after } \\
\text { centrifugation }\end{array} \\
\end{array}$}} \\
\hline & & & & & & & & \\
\hline & $\begin{array}{c}\text { Plaques, } \\
10^{5} / \mathrm{ml} \text {. }\end{array}$ & $\begin{array}{l}\text { Type of } \\
\text { plaque }\end{array}$ & $\begin{array}{c}\text { Plaques, } \\
10^{5} / \mathrm{ml} \text {. }\end{array}$ & $\begin{array}{l}\text { Type of } \\
\text { plaque }\end{array}$ & $\begin{array}{c}\text { Plaques, } \\
10^{5} / \mathrm{mI} \text {. }\end{array}$ & $\begin{array}{l}\text { Type of } \\
\text { plaque }\end{array}$ & $\begin{array}{c}\text { Plaques, } \\
10^{5} / \mathrm{ml} \text {. }\end{array}$ & $\begin{array}{l}\text { Type of } \\
\text { plaque }\end{array}$ \\
\hline 0 & 270 & $\mathbf{L}, \mathbf{S}$ & 150 & $\mathbf{L}$ & 1200 & $\mathrm{~L}, \mathrm{~S}$ & 25 & $\mathbf{L}$ \\
\hline$\frac{1}{2}$ & 250 & $\mathrm{~L}, \mathrm{~S}$ & 130 & $\mathbf{L}$ & 650 & $\mathbf{L}, \mathbf{S}$ & 27 & $\mathbf{L}$ \\
\hline 1 & 170 & $\mathbf{L}$ & 160 & $\mathbf{L}$ & $\mathbf{9}$ & $\mathbf{L}$ & 25 & $\mathbf{L}$ \\
\hline $1 \frac{1}{2}$ & 180 & $\mathbf{L}$ & 150 & $\mathbf{L}$ & 23 & $\mathbf{L}$ & 20 & $\mathbf{L}$ \\
\hline 2 & 150 & $\mathbf{S}$ & 200 & $\mathbf{S}$ & 20 & $\mathbf{L}$ & $\mathbf{3 0}$ & $\mathbf{L}$ \\
\hline $2 \frac{1}{2}$ & 100 & $\mathbf{S}$ & 60 & $\mathbf{S}$ & 15 & $\mathbf{S}$ & 20 & $\mathbf{S}$ \\
\hline 3 & 60 & $\mathbf{S}$ & 0 & - & 25 & $\mathbf{S}$ & 23 & $\mathbf{S}$ \\
\hline 4 & 0 & - & 0 & - & 0 & - & 0 & - \\
\hline
\end{tabular}

$3 \mathrm{hr}$. culture $19(1 / 19)$

$\mathrm{L}=$ plaques of normal size. $\mathrm{S}=$ plaques of subnormal size.

was made to use lawns on which phage counts of a live lysogenic culture were equal to the number of bacteria. Accordingly, bacterial lawns were sown from different dilutions of an $18 \mathrm{hr}$. broth culture of strain 19, and used immediately the lawns were absorbed for phage counts of 3 and $18 \mathrm{hr}$. live broth cultures of strains $19(1 / 19)$ and $19(5 / 19)$ (Table 8$)$. With the $1 / 10$ dilution the phage counts almost equal the viable count of the bacteria, showing that each bacterium was capable of exhibiting its lysogenic state under the cohditions of test. The plaque counts of similar but heat-treated cultures were independent of the amounts of bacterial lawn, though the plaques were larger on the thinner lawns. On the 1/20 lawns accurate plaque counts were difficult.

Table 8. The effect of using different dilutions of a broth culture of strain 19 as the bacterial lawn on phage counts of live lysogenic cultures

Plaques, $10^{6} / \mathrm{ml}$. on lawns seeded from culture diluted

\section{Culture counted}

$3 \mathrm{hr}$. broth culture of $19(5 / 19)$

$18 \mathrm{hr}$. broth culture of $19(5 / 19)$

$3 \mathrm{hr}$. broth culture of $19(1 / 19)$

$18 \mathrm{hr}$. broth culture of $19(1 / 19)$

Heat treated $18 \mathrm{hr}$. culture of $19(1 / 19)$

Bacteria,
$10^{6} / \mathrm{ml}$.
$150 \cdot 0$
$1000 \cdot 0$
$71 \cdot 0$
$1200 \cdot 0$
0

The bacterial lawns were not incubated before use.

$\begin{array}{rrrc}r / 1 & 1 / 5 & 1 / 10 & 1 / 20 \\ 55 \cdot 0 & 45 \cdot 0 & 100 \cdot 0 & 90.0 \\ 170 \cdot 0 & 450 \cdot 0 & 300 \cdot 0 & 350.0 \\ 20 \cdot 0 & 42 \cdot 0 & 55 \cdot 0 & - \\ 120.0 & 350 \cdot 0 & 1000 \cdot 0 & 930.0 \\ 0.9 & 0.75 & 0.8 & 0.45\end{array}$

As a result of these experiments, subsequent phage counts were made on heat-treated bacterial cultures.

The active infection of lysogenic cultures with other phages

Burnet \& McKie (1929) infected a lysogenic culture of $S$. enteritidis with another phage and found that this active infection decreased the yield of phage carried by the lysogenic culture. They concluded that lysis by an unrelated 
phage diminishes the amount of latent phage liberated, and that there is no evidence that the latent phage exists within the lysogenic bacteria as an independent unit.

The experiments were repeated with the lysogenic variants of strain 19 . The technique consisted of adding $0 \cdot 1 \mathrm{ml}$. of an $18 \mathrm{hr}$. broth culture of a lysogenic strain to each of two tubes containing $20 \mathrm{ml}$. of broth. The tubes were incubated at $37^{\circ}$ and, after a suitable previously determined period, an amount of phage, to which the strain was susceptible, was added to one tube and a similar volume of broth to the other. The number of phage particles added was usually about 5-10 times the number of bacteria estimated to be present at the time of addition of the phage preparation. Bacterial and phage counts were made of both cultures immediately before the addition of the infecting phage to confirm that they contained approximately equal numbers of bacteria which were liberating approximately equal numbers of latent phage particles. Incubation was continued and phage counts were made at intervals on $0.1 \mathrm{ml}$. samples after heat treatment of both infecting and latent phage using lawns of the appropriate susceptible strains. The procedure is best illustrated by an example. Strain $19(2 / 19)$ was actively infected with phage $5 / 19$. The yield of the infecting phage, 5/19, was measured on strain $19(2 / 19)$ and the latent phage, 2/19, on strain $19(5 / 19)$. The counts were also carried out using strain 19 as lawn. The two phages, $2 / 19$ and 5/19, were previously titrated on strains $19(2 / 19), 19(5 / 19)$ and 19 to confirm that 2/19, for example, was without effect on strain $19(2 / 19)$ and to determine whether the titration on $19(5 / 19)$ revealed any degree of interference when compared with the same titration on 19. The amounts of the two phages after lysis of the lysogenic cultures by the infecting phages are shown in Table 9. The results with phage $13 / 19$ and strain $19(7 / 19)$ are shown in more detail in Table 10 and in Fig. 3, as they are typical of most of the experiments; and those with phage 5/19 on strain 19 (1/19) in Table 11 and Fig. 4, on account of their exceptional interest.

\section{Table 9. The active infection of lysogenic cultures with other phages}

\begin{tabular}{|c|c|c|c|c|}
\hline \multirow[b]{2}{*}{$\begin{array}{l}\text { Lysogenic } \\
\text { culture }\end{array}$} & \multirow{2}{*}{$\begin{array}{l}\text { Phages used } \\
\text { for active } \\
\text { infection }\end{array}$} & \multicolumn{2}{|c|}{$\begin{array}{l}\text { Infected culture } \\
\text { (particles, } 10^{5} / \mathrm{ml} \text { ) }\end{array}$} & \multirow{2}{*}{$\begin{array}{c}\text { Control culture } \\
\text { (particles, } \\
\left.10^{5} / \mathrm{ml} .\right), \\
\text { latent phage }\end{array}$} \\
\hline & & $\begin{array}{c}\text { Infecting } \\
\text { phage }\end{array}$ & $\begin{array}{c}\text { Latent } \\
\text { phage }\end{array}$ & \\
\hline $19(2 / 19)$ & $5 / 19$ & $7,000 \cdot 0$ & $780 \cdot 0$ & $55 \cdot 0$ \\
\hline $19(2 / 19)$ & $\mathbf{1} / \mathbf{1 9}$ & $8,200 \cdot 0$ & $850 \cdot 0$ & $28 \cdot 0$ \\
\hline $19(1 / 19)$ & $2 / 19$ & $20,000 \cdot 0$ & $\mathbf{3 0 \cdot 0}$ & 3.5 \\
\hline $19(7 / 19)$ & $13 / 19$ & $15,000 \cdot 0$ & $410 \cdot 0$ & $23 \cdot 0$ \\
\hline $19(13 / 19)$ & $7 / 19$ & $20,000 \cdot 0$ & $100 \cdot 0$ & $110 \cdot 0$ \\
\hline $19(5 / 19)$ & $1 / 19$ & $12,000 \cdot 0$ & $150 \cdot 0$ & $130 \cdot 0$ \\
\hline $19(1 / 19)$ & $5 / 19$ & $250 \cdot 0$ & $12,000 \cdot 0$ & $150 \cdot 0$ \\
\hline
\end{tabular}

In the first four experiments in Table 9, active infection with an unrelated phage greatly increased the amount of latent phage liberated from the lysogenic culture by between nine- and thirty-fold in different cases. There was no increase in Exps. 5 and 6, but it is possible that the increase in these cases is 
masked by the early destruction of some of the lysogenic bacteria by the active phage infection. Exp. 7 is particularly interesting, as the addition of phage $5 / 19$ appears to have stimulated an active infection in strain 19 (1/19) with phage, $1 / 19$, with which it was previously only latently infected; large amounts

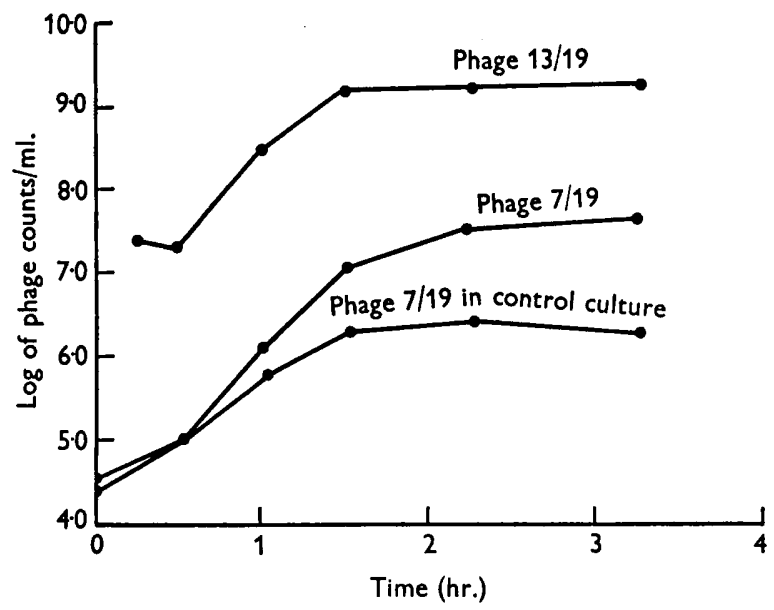

Fig. 3. The active infection of the lysogenic culture $19(7 / 19)$ with phage $13 / 19$. Phage $13 / 19$ was added at $0 \mathrm{hr}$. The control culture of $19(7 / 19)$ was not inoculated with phage $13 / 19$.

Table 10. The effect of infection by phage 13/19 on strain $19(7 / 19)$

Time

Before addition of phage

$\frac{1}{h r}$. after addition

$\frac{1}{2} \quad$, ,

$1 \frac{1}{2} \quad$, ",

$2 \frac{1}{4} \quad$, ,

$3 \frac{1}{8} \quad$, ,

\begin{tabular}{cc}
\multicolumn{2}{c}{$\begin{array}{c}\text { Infected culture } \\
\left.\text { (particles, } 10^{5} / \mathbf{m l} .\right)\end{array}$} \\
$\begin{array}{c}\text { Infecting } \\
\text { phage }\end{array}$ & $\begin{array}{c}\text { Latent } \\
\text { phage }\end{array}$ \\
0 & $0 \cdot 23$ \\
$230 \cdot 0$ & - \\
$180 \cdot 0$ & $1 \cdot 0$ \\
$3,000 \cdot 0$ & $15 \cdot 0$ \\
$17,000 \cdot 0$ & $120 \cdot 0$ \\
$19,000 \cdot 0$ & $350 \cdot 0$ \\
$15,000 \cdot 0$ & $410 \cdot 0$ \\
$30,000 \cdot 0$ & $2,800 \cdot 0$
\end{tabular}

Control culture (particles, $10^{5} / \mathrm{ml}$.), latent phage
$0 \cdot 2$
1.0
$7 \cdot 5$
$20 \cdot 0$
$25 \cdot 0$
23.0
$140 \cdot 0$

Table 11. The effect of infection by phage 5/19 on strain 19 (1/19)

\section{Time}

Before addition of phage

$\frac{1}{4} \mathrm{hr}$. after addition

$\begin{array}{ccc}\frac{1}{2} & , & , \\ \frac{1}{1} & , & , \\ 1 \frac{1}{2} & , ", & , \\ 2 \frac{1}{4} & , & , \\ 18 & ,, & ,\end{array}$

Infected culture

(particles, $10^{5} / \mathrm{ml}$.)

$\begin{array}{rr}\begin{array}{c}\text { Infecting } \\ \text { phage }\end{array} & \begin{array}{c}\text { Latent } \\ \text { phage }\end{array} \\ 0 & 4 \cdot 4 \\ 120 \cdot 0 & 3 \cdot 0 \\ 80 \cdot 0 & 4 \cdot 5 \\ 120 \cdot 0 & 7 \cdot 0 \\ 220 \cdot 0 & 3,000 \cdot 0 \\ 250 \cdot 0 & 12,000 \cdot 0 \\ 270 \cdot 0 & 11,000 \cdot 0 \\ 100 \cdot 0 & 12,000 \cdot 0\end{array}$

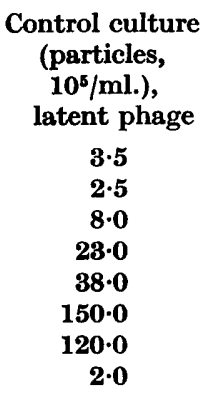


of the phage $1 / 19,12 \times 10^{8}$ particles $/ \mathrm{ml}$, , were present after lysis, but the amount of the infecting phage, 5/19, remained relatively unchanged at $25 \times 10^{6}$ particles/ml. (see also Table 11 and Fig. 4). Phage 5/19 and phage 1/19 produced quite different types of plaques when grown on strain 19; the plaques of $1 / 19$ were clear with a sharp edge and those of $5 / 19$ were semi-clear with a considerable amount of resistant growth and ill-defined edge. Thus it was possible to confirm the counts obtained using $19(1 / 19)$ and $19(5 / 19)$ as lawns by

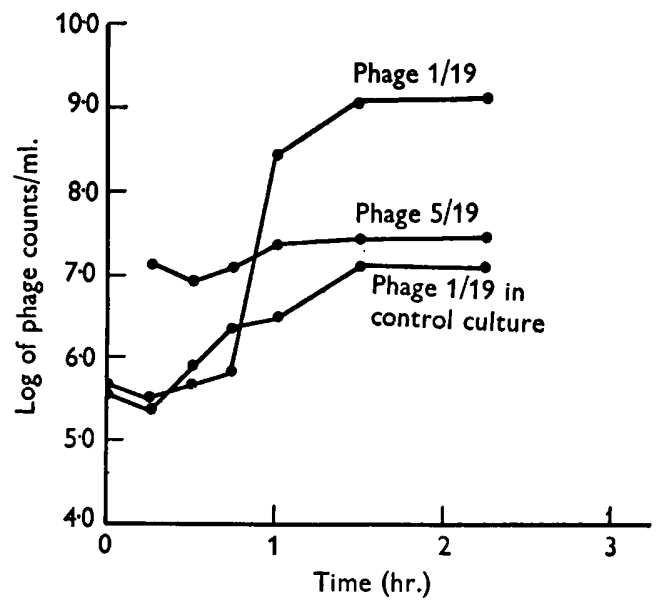

Fig. 4. The active infection of the lysogenic culture 19 (1/19) with phage 5/19. Phage 5/19 was added at $0 \mathrm{hr}$. The control culture of 19 (1/19) was not inoculated with phage $5 / 19$.

counts of the two plaque types on strain 19 instead. The experiment was also repeated with similar results. It is noteworthy that although phage $5 / 19$ was able to induce an active infection of strain $19(1 / 19)$ by its latent phage, it was unable to do so in strain 19 (2/19); and phage 2/19 was similarly unable to stimulate an active infection of strain 19 (1/19) with its latent phage 1/19. The five phages used in the above experiment were used to infect the non-lysogenic strain 19 under exactly the same conditions; the yield of phage was similar to that from the lysogenic strains with the exception, of course, of the yield of $5 / 19$ on $19(1 / 19)$.

\section{Observations on bacterial cultures rendered resistant to more than one phage}

The resistant variants of strain 19 were made resistant to other phages. The preparation of doubly-resistant strains was, unlike that of singly-resistant strains, not without considerable difficulty. Lysis by the second phage occurred in the usual way but, when the resistant growth produced by continued incubation was plated, the resulting colonies were often of the nibbled variety, indicating that they were actively infected with phage. Broth cultures from these colonies were proved to contain both phages, and when they were replated, yielded normal as well as nibbled colonies; cultures from these normal colonies were now fully susceptible to the second phage and were shown to 
carry only the first phage to which they had been made resistant. The true doubly-resistant variants were plated several times before determining the phages with which they were now latently infected. The determination of latent infection is best illustrated by an example. Strain 19 (1/19) was made resistant to phage 2/19. Cultures of the doubly-resistant variant that resulted were examined at different periods of incubation; plate lysis of strain 19 (1/19) by these cultures after heat treatment was taken to indicate the presence of phage $2 / 19$, and lysis of strain $19(2 / 19)$ as indicative of the presence of phage $1 / 19$. The doubly-resistant strains were numbered thus: strain $19(1 / 19+2 / 19)$, the

Table 12. The carriage of phages by strains made resistant to two phages

$\begin{array}{ccc}\begin{array}{c}\text { Doubly-resistant } \\ \text { variant* }\end{array} & \begin{array}{c}\text { No. of variants } \\ \text { tested }\end{array} & \begin{array}{c}\text { Phages } \\ \text { carried }\end{array} \\ 19(1 / 19+2 / 19) & 21 & 1 / 19 \\ 19(2 / 19+1 / 19) & 18 & 2 / 19 \\ 19(13 / 19+7 / 19) & 13 & 13 / 19 \\ 19(2 / 19+5 / 19) & 1 & 2 / 19,5 / 19 \\ 19(5 / 19+2 / 19) & 1 & 5 / 19 \\ 19(5 / 19+1 / 19) & 15 & 5 / 19\end{array}$

* The phages to which the strains were first made resistant are placed first in the brackets.

phage to which strain 19 was first made resistant, preceding the phage, $2 / 19$, to which it was subsequently made resistant. The results of some of these experiments are given in Table 12. With the exception of strain $19(2 / 19+5 / 19)$ the doubly-resistant variants carried only the first phage to which they had been made resistant. The six types of variants were subcultured several times over a period of 3 months, single colonies being picked on each occasion; no change of resistance or phage-carriage was noted. It was originally intended to make eight doubly-resistant strains, but it was found impossible despite repeated attempts to make permanent resistant variants of strain $19(7 / 19)$ to phage $13 / 19$ and strain $19(1 / 19)$ to phage 5/19. The only kind of resistant culture produced in these cases was of the nibbled colony type which after a few subcultures broke down to yield colonies which did not carry the second phage and which were fully susceptible to it.

Naturally occurring lysogenic cultures were made resistant to other phages to determine whether their status was similar to that of the artificial doublyresistant strains. They were equally difficult to make. Of five doubly-resistant variants, two were resistant to, but did not carry, the phage to which they had been made resistant.

\section{DISCUSSION}

There is much conflicting evidence about the absorption of homologous phage by phage-resistant strains; some workers contend that these strains do absorb phage while others deny it. My results suggest that both contentions are correct: some strains, e.g. strain 19 (1/19), absorbed the phage whereas other strains appeared to be unable to do so. The occurrence of absorption appeared to depend more on the phage than on the bacterium; all the lysogenic variants of strain 19 resistant to the same phage or to phages shown to be identical by cross-resistance tests exhibited the same kind of phage-bacterium growth curve, 
and variants of other strains (e.g. strains 30 and 2 ) resistant to the same phages behaved in a similar fashion.

A most interesting effect was obtained when a lysogenic culture was used as the bacterial lawn. When the carried phage was identical with, or closely similar to, the phage that was being counted, there were, of course, no plaques; and again, when the phage carried by the lysogenic culture was unrelated to the phage that was being counted, the plaques were similar in size to those obtained when a non-lysogenic culture was used as the lawn. However, when the lysogenic culture carried a phage related to the phage being , counted, partial interference often resulted, indicated by the appearance of plaques of subnormal size. A variation of the conditions of test, such as an increase in the amount of bacterial lawn, was sometimes sufficient to inhibit the formation of such plaques. As some of the methods of phage typing depend on the pattern of reactions that some strains show when tested with a number of phages, it is apparent that the relationship of the phages carried by lysogenic strains being typed to the typing phages can account for some strains being regarded as separate types and can also be confusing unless a strict standard method of test be followed.

The observations on the active infection of lysogenic strains do not agree with the conclusion of Burnet \& McKie (1929) that lysis by an unrelated phage diminishes the amount of latent phage liberated by a lysogenic strain; usually there was a considerable increase in the yield of phage. The number of latent phage particles liberated by some of the lysogenic strains was probably approximately equal to the number of bacteria present in the lysogenic culture before lysis by the unrelated phage. This, however, could not be confirmed owing to the impossibility of counting the number of viable bacteria that had been actively infected with phage. In fact, the results support the view that phage may exist within the bacterial cell as an intrinsic unit rather than as, or in addition to, some form of phage precursor. The stimulation of an active infection in the lysogenic culture 19 (1/19) with the phage it was carrying, $1 / 19$, by the addition of phage $5 / 19$ was particularly interesting, as it bears some resemblance to the change from latent to active infection that may sometimes occur in virus diseases of animals.

My thanks are due to Dr Joan Taylor and Mr A. Buxton for providing me with the cultures of salmonella used in this work.

\section{REFERENCES}

BAIL, O. (1923). Versuche über die Vielheit von Bakteriophagen. Z. ImmunForsch. $38,57$.

Burnet, F. M. (1932). Lysogenicity as a normal function of certain Salmonella strains. J. Path. Bact. 35, 851.

Burnet, F. M. \& MCKIE, M. (1929). Observation on a permanently lysogenic strain of B. enteritidis Gaertner. Aust. J. exp. Biol. med. Sci. 6, $27 \%$.

Fisk, R. H. (1942). Studies on staphylococci. I. Occurrence of bacteriophage carriers amongst strains of Staphylococcus aureus. J. infect. Dis. 71, 153.

Mrles, A. A. \& Misra, S. S. (1938). The estimation of the bactericidal power of the blood. J. Hyg., Camb., 46, 82. 